\title{
AS FORMAS \\ DE INTERVENÇÃO \\ DO PROFESSOR \\ NO TEXTO \\ DO ALUNO \\ E A CONSTRUÇÃO \\ DA INTERSUBJETIVIDADE
}

\section{LAS FORMAS DE INTERVENCIÓN DEL PROFESOR EN EL TEXTO DEL ALUMNO Y LA CONSTRUCCIÓN DE LA INTERSUBJETIVIDAD}

THE FORMS OF TEACHER INTERVENTION IN THE STUDENT'S TEXT AND CONSTRUCTION OF INTERSUBJECTIVITY

\author{
Elisane Regina Cayser* \\ Luciana Maria Crestani** \\ Marlete Sandra Diedrich*** \\ Universidade de Passo Fundo
}

\begin{abstract}
RESUMO: Sabe-se que, na maioria das vezes, a produção textual no ambiente escolar constitui-se em um processo discursivo artificializado e, de certo modo, vazio em termos de interação intersubjetiva. O aluno escreve para obter nota. O professor corrige para atribuir nota. A isso se resume o propósito interacional desencadeado com a produção do enunciado. Tal perspectiva deixa a desejar quando se leva em conta que o objetivo primeiro da escola é desenvolver a competência discursiva dos alunos e que isso se efetiva através de práticas de escrita e reescrita mediadas pelo professor. Nesse sentido, à luz de concepções de Benveniste (2005) acerca da subjetividade na linguagem e de Bakhtin (2003) sobre enunciado/texto como unidade da comunicação discursiva, analisam-se as formas de correção textual elencadas por Ruiz (2010) enquanto estratégias de intervenção do professor no texto do aluno, com vistas a discutir o processo de escrita e reescrita numa abordagem enunciativa. A análise aponta que, dependendo das

\footnotetext{
* Doutoranda em Letras, professora no Curso de Letras da Universidade de Passo Fundo (UPF) e coordenadora da Área de LínguaPortuguesa. E-mail: ecayser@upf.br.

** Doutora em Letras, professora no Curso de Letras e no Programa de Pós-graduação em Letras da Universidade de PassoFundo(UPF). E-mail: lucianacrestani@upf.br. 
estratégias de intervenção utilizadas, diferentes graus de interação se estabelecem, sendo que, em alguns casos, ela é quase que apagada.

PALAVRAS-CHAVE: Subjetividade na linguagem. Interação. Produção textual. Escritura e reescritura de textos.

ABSTRACT: It is known that, in most cases, text production in the school environment is mostly formed by an artificialized discursive process, and somehow empty in terms of intersubjective interaction. The student writes to get a grade. The teacher corrects it to give a grade. This summarizes the interactional purpose triggered by the production of enunciation. Such perspective falls short considering the primary objective of the school: to develop the discursive competence of students effectively through writing and rewriting practices mediated by the teacher. Hence, in the light of concepts by Benveniste (2005) on the subjectivity in language, and by Bakhtin (2003) about enunciation/text as discursive communication units, the forms of text corrections listed by Ruiz (2010) as teacher intervention strategies in the student's text were analyzed in order to discuss the writing and rewriting process on an expository approach. The analysis shows that, depending on the intervention strategies used, different degrees of interaction are established, and, in some cases, almost erased.

KEYWORDS: Subjectivity in language. Interaction. Text production. Writing and rewriting of texts.

RESUMEN: Se sabe que, la mayoría de las veces, la producción textual en el ambiente escolar se constituye por un proceso discursivo artificial y, de cierto modo, vacío en términos de interacción intersubjetiva. El alumno escribe para obtener nota. El profesor corrige para atribuir nota. A esto se resume el objetivo de interacción desencadenado en la producción del enunciado. Tal perspectiva deja que desear cuando se toma en cuenta que el objetivo primero de la escuela es desarrollar la competencia discursiva de los alumnos y de que esto se efectiva a través de prácticas de escritura y reescritura mediadas por el profesor. En este sentido, a la luz de conceptos de Benveniste (2005) sobre la subjetividad en el lenguaje y de Bakhtin (2003) sobre enunciado/texto como unidad de comunicación discursiva, se analizan las formas de corrección textual enumeradas por Ruiz (2010) como estrategias de intervención del profesor en el texto del alumno, para discutir el proceso de escritura y reescritura en un abordaje enunciativo. El análisis muestra que, dependiendo de las estrategias de intervención utilizadas, se establecen diversos grados de interacción y, en algunos casos, es casi anulada.

PALABRAS CLAVE: Subjetividad en el lenguaje. Interacción. Producción textual. Escritura y reescritura de textos.

\section{INTRODUÇÃO}

Apesar dos avanços teóricos ligados ao ensino e à aprendizagem de línguas, ainda persistem, em muitas situações escolares, práticas pouco adequadas e ineficazes, as quais não só não levam o aluno à ampliação da sua competência comunicativa como, especialmente, afastam-no do objeto linguístico, por gerarem nele uma verdadeira aversão pela língua e por tudo o que diz respeito a ela.

A perspectiva reducionista do ensino de língua, analisando-se frases e, não raras vezes, palavras de forma descontextualizada, rompe com o entendimento mais básico sobre a linguagem - o de que ela funciona para que as pessoas interajam. Dessa forma, não servindo para a interação entre pessoas, na concepção escolar implícita em diferentes práticas, a linguagem passa a ser tomada pelo aluno como objeto passível de ser dissecado e sobre o qual são propostas atividades, na maioria das vezes, mecânicas, ou para cuja execução não se exige nenhum raciocínio mais apurado.

Especificamente quanto à produção de textos, além de não contemplar os diferentes gêneros que circulam socialmente, a escola, na maioria das vezes,privilegia atividades que não envolvem a autoria legítima, no sentido de uma produção discursiva com vistas à interação com outro sujeito a quem se tem algo a dizer. Essa escrita distante do cotidiano das pessoas, deslocada da própria essência da linguagem, passa, então, a focar-se na memorização de regras gramaticais. Escrever bem, nessa instância, consiste em não cometer erros dessa ordem.

Numa situação cotidiana de comunicação, o texto - seja ele oral ou escrito - é a instância que une dois polos: aquele que diz/escreve e aquele que ouve/lê. No entanto, a prática artificializada e inexpressiva da linguagem faz com que surja uma escrita vazia, sem 
qualquer evidência de relação com alguma situação comunicativa qualquer. Em outros termos, tem-se uma escrita sem valor interacional, em que está ausente o $\mathrm{eu}$ que diz e, na outra ponta, o $t u$ para o qual se dirige a enunciação, perspectiva essa emprestada de Benveniste (2005) e de Bakhtin (2003).

É nessa dimensão que ganham relevância os procedimentos adotados pelo professor tanto no que respeita ao encaminhamento da produção textual quanto do momento posterior à produção do texto. Esse tratamento dado ao texto produzido pelo aluno tem de deixar clara uma concepção de língua enquanto atividade de interação entre sujeitos, ou seja, uma visão interacionista e funcional da linguagem, segundo a qual a língua é atualizada a cada interação intersubjetiva, na qual entra em jogo a parceria para a produção dos sentidos. Nessa perspectiva, o trabalho com produção de textos não pode excluir do processo o leitor, o destinatário, uma vez que sem que exista o $t u$, inexiste também o eu que enuncia. Se a palavra vem de alguém, ela se dirige a alguém - sem essa dualidade, não existe interação, e o texto descaracteriza-se de sua função primordial.

Considerando tais premissas é que este trabalho se propõe a discutir as formas de intervenção do professor no texto produzido pelo aluno, especialmente considerando a relação e eu/tu instaurada entre o sujeito produtor do texto e o professor, o leitor imediato - e, na maioria das vezes, único - do texto. Para tanto, à luz de concepções de Benveniste (2005) sobre a subjetividade na linguagem e de Bakhtin (2003) sobre enunciado/texto como unidade da comunicação discursiva, analisam-se as formas de correção textual elencadas por Ruiz (2010) enquanto estratégias de intervenção do professor no texto do aluno, com vistas a uma abordagem enunciativa do processo de escrita e reescrita.

\section{A ENUNCIAÇÃO SEGUNDO BENVENISTE: O SUJEITO CONSTITUÍDO NA E PELA LINGUAGEM}

É na enunciação - ou seja, no discurso - que a subjetividade se manifesta. O locutor converte a língua em discurso, colocando-se nele como sujeito e instituindo um outro, implícito ou explícito, ao qual se dirige. Diz Benveniste (2005, p. 286), no texto Da subjetividade da linguagem:

\footnotetext{
A consciência de si mesmo só é possível se experimentada por contraste. Eu não emprego $e u$ a não ser dirigindome a alguém, que será na minha alocução um $t u$. Essa condição de diálogo é que é constitutiva da pessoa, pois implica em reciprocidade - que $e u$ me torne $t u$ na alocução daquele que por sua vez se designa $e u$. (grifos do autor).
}

É nessa alternância entre o $\mathrm{eu}$ e o $t u$, sempre únicos e que podem ter intercambiadas suas posições, que se instaura a intersubjetividade da/na enunciação, proposta por Benveniste (2005). O eu fora da linguagem é inatingível. É o exercício da língua que faz o homem subjetivar-se, colocando-se como sujeito do discurso. E é a consciência do outro que desvela a intersubjetividade, dada a impossibilidade de dizer se não para uma instância diferente: o $t u$. O eu só pode ser eu na premência de um $t u$. Há um jogo de relações complementares nisso, sendo que um não existe na ausência do outro: $e u$ se propõe como $e u$ a um $t u$ que, por seu turno, passa a ser $e u$ e instaura o outro como $t u$.

A relação de pessoa se dá, portanto, no discurso, por meio dos pronomes pessoais eu/tu, que só ganham sentido quando pronunciados pelo sujeito, sendo, fora disso, desprovidos de uma referência determinada - o referente só é dado a saber na enunciação, haja vista que tais elementos não se ligam a um referente sempre idêntico, mas sim a um sujeito único. A referência, então, gira em torno de quem diz. Especificamente quanto à pessoa, sem o sujeito, o eu/tu é desprovido de sentido, não referindo nada. Daí dizer-se que são os pronomes pessoais que instauram a subjetividade no discurso, inclusive porque não pertencem à realidade do mundo, mas sim à realidade do discurso.

Essas concepções, abordadas por Benveniste (2005) em Problemas de linguística geral I, norteiam as reflexões sobre a categoria de pessoa na teoria da enunciação, quando se faz a distinção entre as pessoas $e u / t u$ e a não pessoa $e l e$. Dessa relação entre o $e u$ que enuncia e o $t u$ ao qual o $e u$ se dirige, elementos que são, a cada vez, únicos, emerge o que Benveniste chama de correlação

Fórum linguistic., Florianópolis, v. 13, n.3, p.1415-1429, jul./ set.2016. 
intersubjetiva, considerada como uma categoria constitutiva do diálogo, sendo essa, portanto, uma condição da linguagem humana. Afinal, não se enuncia sem que haja sujeitos que interajam:

[...] o sujeito se serve da palavra e do discurso para representar-se a si mesmo, tal como quer ver-se, tal como chama o "outro" a comprovar. [...] Pela simples alocução, aquele que fala de si mesmo instala o outro nele e dessa forma se capta a si mesmo, se confronta, se instaura tal como aspira a ser, e finalmente se historiza nessa história incompleta ou falsificada. [...] A linguagem, assim, é utilizada aqui como palavra, convertida nessa expressão da subjetividade iminente e evasiva que constitui a condição do diálogo. A língua fornece o instrumento de um discurso no qual a personalidade do sujeito se liberta e se cria, atinge o outro e se faz reconhecer por ele. Ora, a língua é uma estrutura socializada, que a palavra sujeita a fins individuais e intersubjetivos, juntando-lhe assim um perfil novo e estritamente pessoal. A língua é um sistema comum a todos; o discurso é ao mesmo tempo portador de uma mensagem e instrumento de ação. Nesse sentido, as configurações das palavras são cada vez únicas, embora se realizem no interior - e por intermédio - da linguagem. Há, pois, antinomia no sujeito entre o discurso e a língua (BENVENISTE, 2005, p. 84).

No texto A natureza dos pronomes, Benveniste afirma que a realidade à qual se referem eu ou tu é, como dito anteriormente, unicamente a realidade de discurso, não remetendo à realidade, mas à enunciação, refletindo, assim, o seu próprio emprego. Tais formas remetem sempre à enunciação, a cada vez única. Assim, elas explicitam a relação entre a enunciação e a intersubjetividade própria da comunicação: "É identificando-se como pessoa única pronunciando eu que cada um dos locutores se propõe alternadamente como 'sujeito'”(BENVENISTE, 2005, p. 280-281, grifo do autor).

A relação $e u$ - $t u$, dessa maneira, materializa a dimensão subjetiva da linguagem, sendo que não é possível empregar $e u$ senão na interlocução com outrem, que será um $t u$. A dialogicidade, então, é constitutiva dessa relação, dado que é essencial a reciprocidade, nas palavras de Benveniste (2005, p. 286): “[...] que eu me torne tu na alocução daquele que por sua vez se designa eu. [...] A polaridade das pessoas é na linguagem a condição fundamental, cujo processo de comunicação, de que partimos, é apenas uma consequência totalmente pragmática”. Em outros termos, a proposta de Benveniste é que a subjetividade e a intersubjetividade na linguagem sejam reconhecidas enquanto constitutivas do diálogo e do sujeito que se constitui na e pela linguagem, produzindo sentidos.

Enfim, para Benveniste (2005), é no discurso que os sujeitos expressam a sua relação com o mundo, por meio da referência daquele que diz, o que possibilita a correferência por parte do outro. Essa alternância de papéis denomina-se intersubjetividade, sendo que a referência sempre deve ser analisada na perspectiva daquele que enuncia. A reversibilidade $e u / t u$, volta-se a dizer, não diz respeito a seres do mundo, mas sim a instâncias próprias e inerentes ao funcionamento discursivo.

O sujeito, ao instaurar-se discursivamente como eu e dirigir-se a $t u$, sempre tem um propósito comunicativo. Dessa forma, quando um determinado arranjo é feito a partir da língua, as formas linguísticas escolhidas e combinadas acabam por situar aquele que fala no seu próprio ato enunciativo, ou seja, quando faz determinada escolha linguística, o enunciador transpõe uma forma disponível na língua para o seu discurso, dando a ela um significado particular, própria daquele momento enunciativo.

Para detalhar essa questão da interação por meio do enunciado, desenvolve-se, a seguir, o tópico relacionado aos estudos de Bakhtin acerca do tema.

\section{O ENUNCIADO COMO UNIDADE DA INTERAÇÃO DISCURSIVA}

Ao tratar o enunciado como a real unidade da comunicação discursiva, Bakhtin (2003) explica que um traço constitutivo desse é o caráter responsivo, marcado pela alternância entre sujeitos. Isso porque, ao produzir um enunciado, o enunciador espera uma resposta (de compreensão, de aceitação, de recusa, de complementação etc.) do enunciatário a quem o texto se dirige. 
Desde o início [...] o enunciado se constrói levando em conta as atitudes responsivas, em prol das quais ele, em essência, é criado. O papel dos outros, para quem se constrói o enunciado, é excepcionalmente grande, como já sabemos. Já dissemos que esses outros, para os quais o meu pensamento pela primeira vez se torna um pensamento real [...] não são ouvintes passivos mas participantes ativos da comunicação discursiva. Desde o início o falante aguarda a resposta deles, espera uma ativa compreensão responsiva. É como se todo o enunciado se construísse ao encontro dessa resposta. (BAKHTIN, 2003, p. 301, grifo do autor).

Nesse sentido, o outro, o tu, exerce papel essencial no processo de produção do enunciado, não podendo, de forma alguma, ser dele excluído. Não apenas as escolhas linguísticas, mas todas as escolhas (semânticas, sintáticas, de gênero textual, de estratégias argumentativas etc.) são feitas tendo em vista a atitude responsiva de um determinado enunciatário. Conforme o teórico russo,

[...] Ao falar, sempre levo em conta o fundo aperceptível da percepção do meu discurso pelo destinatário: até que ponto ele está a para da situação, dispõe de conhecimentos especiais de um dado campo cultural da comunicação; levo em conta as suas concepções e convicções, os seus preconceitos (do meu ponto de vista), as suas simpatias e antipatias - tudo isso irá determinar a ativa compreensão responsiva do meu enunciado por ele. Essa consideração irá determinar também a escolha do gênero do enunciado e a escolha dos procedimentos composicionais e, por último, dos meios lingüísticos, isto é, do estilo do enunciado. (BAKHTIN, 2003, p. 302, grifo do autor).

Disso advém o conceito de coenunciação, diretamente relacionado à intersubjetividade discursiva de que trata Benveniste (2005), na medida em que as escolhas enunciativas do eu são feitas tendo em conta o tu a quem se destina o discurso. Nesse sentido, o tué sempre coenunciador, pois é em razão dele que se escolhem determinadas estratégias enunciativas e não outras. Afinal, "[...] não é a mesma coisa fazer um texto para crianças ou para adultos, para leigos numa dada disciplina ou para especialistas nela” (FIORIN, 2010, p. 163).

Neste estudo, toma-se texto, portanto, na perspectiva bakhtiniana de enunciado materializado em forma de um gênero. Assim entendido, o texto constitui-se de características discursivas intrínsecas, como o caráter dialógico, a responsividade e a relativa conclusibilidade do dito, a qual demarca também o momento da alternância entre $e u-t u$.

Isso não quer dizer que mecanismos linguísticos (do sistema da língua) não mereçam, também eles, atenção no momento da produção textual - uma vez que é através deles que se materializa/textualiza o discurso e a propriedade no emprego desses contribui para a inteligibilidade do todo de sentido -, mas sim que, tomado como unidade da comunicação discursiva, o texto não pode servir apenas a análises formais e gramaticais, fechando-se em seus aspectos significantes.

A propósito, no capítulo O problema do texto na lingüística, na filologia e em outras ciências humanas, ao refletir sobre o texto como enunciado, Bakhtin (2003) explica que todo texto tem dois polos. O primeiro está relacionado ao fato de que "[...] por trás de cada texto está o sistema da linguagem. A esse sistema corresponde no texto tudo o que é repetido e reproduzido, tudo o que pode ser repetido e reproduzido, tudo o que pode ser dado fora de tal texto (o dado)". Concomitantemente, o segundo polo diz respeito ao fato de que "[...] cada texto (como enunciado) é algo individual, único e singular, e nisso reside todo o seu sentido (sua intenção em prol do qual foi criado)." (BAKHTIN, 2003, p. 309-310). É nesta última perspectiva que o texto é unidade da comunicação discursiva.

A questão da autoria está também relacionada a esse segundo polo. A vontade discursiva do falante se materializa num determinado gênero marcado por escolhas enunciativas (semânticas, sintáticas, linguísticas etc.) particulares, projetadas no texto em função da imagem que o $e u$ tem do $t u$. Mais uma vez se mostra a importância do enunciatário, do tu, no processo de produção do enunciado/texto.

No processo de produção textual na escola, o professor será o tu a quem o texto se destina e, portanto, o aluno (o eu) fará suas escolhas com base na imagem que tem daquele como enunciatário: do que supõe que ele queira ouvir/ler, do que supõe que ele já saiba (ou não) sobre o objeto do discurso, do que pode ou não ser dito àquele sujeito tendo em conta a hierarquia e a situação em 
que se encontram, das suas preferências linguísticas etc. Todas as escolhas serão feitas esperando uma resposta por parte desse enunciatário. Nesse contexto, parece correto dizer que a produção discursiva se tornará mais árdua - e estigmatizada - se o aluno tiver uma imagem do professor - seu enunciatário imediato - apenas como avaliador do texto, e do texto como mero objeto em que se observam aspectos formais e gramaticais para gerar uma nota.

\section{A AVALIAÇÃO DOS TEXTOS ESCOLARES E A REESCRITURA}

Na escola, cabe ao professor avaliar, decidindo sobre estratégias e tópicos a enfocar. Cabe ao aluno, por seu turno, submeter-se à avaliação, passivamente, sem qualquer participação mais atuante enquanto avaliador do seu desempenho em determinada área. Não se tem, portanto, o olhar do eu sobre si mesmo - somente o olhar do outro vale, diferentemente do que acontece na vida, em que um indivíduo procede, o tempo todo, a feedbacks sobre seu próprio desempenho, o que é formulado, obviamente, a partir da relação estabelecida com o outro, da reação dele diante de um comentário ou de um pedido, por exemplo. De qualquer forma, é o sujeito que, via de regra, se autoavalia, de modo a reforçar comportamentos - inclusive linguísticos -, reformulá-los ou a abandonálos.

Essa dinâmica tão comum no cotidiano ganha, no contexto escolar, outra dimensão, reduzida e infrutífera, porque se acaba em si mesma: a correção. O termo "correção" já carrega duas implicações para a prática escolar: em primeiro lugar, como afirma Antunes (2009), só se corrige aquilo que está errado. Não se trata, portanto, de melhorar algo, ou de adequar uma reflexão a um determinado propósito, mas sim de analisar se tal reflexão está correta ou errada. Ponto. A segunda implicação diz respeito ao fato de que "alguém” corrige - o professor, cabendo a ele, unilateralmente, julgar o produto, o objeto determinado.

A avaliação, porém, tem outro caráter. Se bem conduzida, ela pode - em relação à produção de textos, em específico - levar o aluno a perceber suas habilidades e o que ainda falta para ampliá-las. Já quanto ao professor, o processo avaliativo representa um recurso valiosíssimo para programar futuras atividades no ensino da língua, de tal maneira a contemplar aspectos detectados como problemáticos no texto produzido pelos alunos. Isso implica, obrigatoriamente, tanto no caso do professor como do aluno, encarar a avaliação de um texto como um dos momentos da produção, mas não o único, tampouco o último. Não é a atribuição de uma nota ou de um conceito que leva o aluno a repensar a forma linguística empregada, os elementos ligados à textualidade - coesão, coerência do que é dito, carga de informação oferecida ou relações intertextuais estabelecidas - ou à pertinência do que se diz no contexto comunicativo em jogo, incluindo a adequação ao gênero textual, à situação interlocutiva prevista, dentre outros aspectos. A nota tampouco oferece pistas desta ordem ao professor.

A avaliação cooperativa de um texto leva professor e aluno a trabalharem juntos rumo à autonomia daquele que escreve. Afinal, $o$ objetivo da escola em termos de produção textual deveria ser o de formar sujeitos autônomos, capazes de monitorarem a própria produção - tanto oral quanto escrita - em busca de uma maior e melhor interação com o outro, atingindo seus propósitos comunicativos.

De qualquer forma, para que essa meta seja atingida, é preciso redimensionar a avaliação, como já dito, reconhecendo que um texto é produzido por um sujeito para outro sujeito, mesmo que virtual. Em outros termos, é preciso reconhecer que num texto há uma enunciação em jogo, e, portanto, há dois sujeitos que devem, a partir do material linguístico explicitado, negociar os sentidos implícitos.

O professor tem de se colocar- no momento de leitura do texto do aluno - como um enunciatário, e não como um "apontador de erros". Essa postura possibilita ao aluno que ele ocupe o papel de eu que enuncia, assumindo-se enquanto sujeito que tem o que dizer e que quer fazê-lo para interagir com o outro.

É nessa perspectiva de troca de posições entre o $e u$ e o $t u$ que reside a importância da reescritura textual. Reconstruir um texto através da mediação do professor permite ao aluno distanciar-se do texto para avaliá-lo, alternando-se entre a posição de autor e de leitor. A leitura do professor possibilita que ele perceba a leitura que o outro é capaz de fazer a partir das pistas deixadas no texto, 
compreendendo melhor os recursos utilizados e os efeitos criados, bem como descobrindo outros dos quais poderia ter lançado mão para alcançar determinado efeito de sentido.

\section{UM OLHAR ENUNCIATIVO SOBRE AS FORMAS DE INTERVENÇÃO DO PROFESSOR NO TEXTO DO ALUNO}

O outro constitui o texto, na medida em que dá acabamento a ele. Isso não só no sentido de ter uma atitude interpretativa/responsiva acerca do que dito pelo $e u$, mas, como já se apontou, no sentido de uma construção colaborativa - em algum grau - na produção do enunciado, já que o $t u$ determina as escolhas enunciativas do $e u$. A enunciação é, na verdade, sempre coenunciação.

Nesse sentido, o olhar do professor sobre o texto, se pautado em questões relacionadas ao que se diz, a quem se diz, como se diz, ou seja, se voltado à prática discursiva enquanto prática social, de interlocução, de interação verbal, pode constituir-se em valioso recurso para a qualificação dos textos, por meio da reescritura textual.

Para que isso ocorra, o texto precisa ser visto como unidade de sentido, e não como mera tarefa escolar, como produto - e, portanto, pronto, acabado. Daí a importância da reescritura, que denota uma perspectiva da escrita num caráter processual, de interlocução entre sujeitos.

Como lembra Bakhtin (2003, p. 275), "[...] o falante termina o seu enunciado para passar a palavra ao outro ou dar lugar à sua compreensão ativamente responsiva”. Nesse sentido, ao finalizar seu texto, "[...] o aprendiz (o aluno), na escola, ao dar lugar à compreensão responsiva ativa do outro (o professor), espera dele algum retorno, não um retorno qualquer, mas algo capaz de permitir uma dialogia, entendendo-a como um momento de produção de sentidos, de dizeres e de trocas significativas" (LEAL, 2008, p. 55). Se assim não o for, a atividade de produção perde o caráter de interação.

Da intervenção do professor no texto produzido pelo aluno e da forma como ela for conduzida, priorizando um ou outro tópico, dependerão as alterações que o aluno deverá fazer. No caso de a atenção estar voltada para os aspectos ortográficos apenas, será este o foco do aluno na reescrita. Por outro lado, incluindo-se na análise feita pelo professor questões relacionadas à intenção pretendida, à adequação do texto ao gênero textual determinado, à relação daquele texto com outros textos, dentre outros aspectos de ordem da enunciação, da textualização e da pragmática, o processo de reescritura tenderá a ampliar a competência discursiva do aluno, trazendo ao nível consciente os recursos que a língua oferece e, especialmente, fazendo-o assumir-se enquanto sujeito que tem algo a dizer a alguém.

A reescrita, assim, sobretudo se pautada em aspectos de fato relevantes para a construção textual, mostra-se uma estratégia eficiente que leva o aluno a um engajamento na sua própria aprendizagem, o que o leva a avançar em termos de proficiência textual.

A alternância de papéis enunciador/enunciatário criada por meio da leitura do professor e do encaminhamento para a reescritura faz com que o aluno consiga se colocar na posição do outro para que, assim, vendo o seu texto de uma forma distanciada e crítica, redimensione estratégias, reconstrua segmentos, explore novas estratégias, e - inclusive, por que não? - adapte o texto às normas do texto escrito.Esse deslocamento de sujeito produtor para sujeito leitor do seu próprio texto, porém, como já dito, dependerá do encaminhamento dado pelo professor, o qual, por sua vez, demonstra na crítica feita ao texto a sua concepção de língua e de texto para não dizer a sua concepção da própria escola.

Parece claro que o aluno não passará, na reconstrução, a atentar para a adequação vocabular no caso de o professor privilegiar apenas a ortografia. Da mesma forma, é improvável que ele se dê conta de uma incoerência se o professor só se detém às normas de colocação pronominal, por exemplo.

Na sequência, apresentam-se os principais tipos de intervenção do professor no pós-texto, elencados por Ruiz (2010), e, com base nas estratégias utilizadas em cada uma das formas, discutem-se a provável consequência pedagógica desencadeada e, especialmente, a intersubjetividade construída na relação entre o professor e o aluno no processo de reescrita.

Fórum linguistic., Florianópolis, v.13,n.3,p.1415-1429, jul./ set.2016. 
Os exemplos utilizados para ilustrar as formas de correção são de arquivos pessoais das autoras. Os textos são resultantes de produções de alunos do terceiro ano do ensino médio, e os apontamentos/correções visam apenas a exemplificar as intervenções de diferente natureza mencionadas por Ruiz (2010), sendo todos os textos pertencentes à tipologia dissertativa ${ }^{1}$.

\subsection{CORREÇÃO RESOLUTIVA}

Na correção resolutiva, tem-se o que mais se aproxima, de fato, da acepção da expressão correção de texto, distanciando-se, assim, do que se entende por avaliar o texto.

Nela, é o professor que efetua a correção dos erros, reescrevendo palavras e trechos inteiros, até mesmo interpretando segmentos pouco claros e reconstruindo-os, isentando o aluno dessa tarefa.

O professor pode atuar de três maneiras: a) fazendo anotações no corpo do texto: acrescentando a forma resolutiva do problema no espaço entre as linhas onde acontece o problema, acrescentando um termo, por exemplo, substituindo uma expressão ou todo um segmento ou mesmo riscando a forma problemática; b) apontando problemas na margem do texto, onde escreve a forma correta; c) redigindo corretamente, no espaço logo abaixo do texto, as palavras ou segmentos problemáticos ao longo do texto.

A intervenção do professor é direta, na medida em que ele mesmo trata de solucionar os problemas detectados. Por isso, ele acaba provavelmente sem ter consciência disso, em muitos casos - por assumir o compromisso de qualificar o texto, em vez de passá-lo ao próprio aluno - autor do texto.

"Corrigido" um texto nesses moldes, a impressão que se tem é que o texto passa - por meio da ação do professor - da sujeira para a assepsia e o brilho, excluídas que foram as impurezas de toda ordem. A questão que se coloca, porém, é: qual o resultado prático disso para a ampliação da capacidade de produção de textos do aluno?

Neste tipo de correção, não só o professor aponta o local onde o aluno deve operar como diz como ele deve operar. Ocorre, porém, que quem reescreve o texto é o professor. Pouco restará ao aluno fazer após a intervenção do professor, senão passar a limpo o texto. A reescritura passa, então, a ser uma atividade mecânica de cópia. E não raras vezes se tem uma cópia em que os mesmos erros cometidos na primeira versão são repetidos, a despeito das anotações do professor, ou outros erros são cometidos, o que pode ser atribuído ao descompromisso do aluno com a qualificação do seu texto, descompromisso esse indiretamente incentivado pela estratégia de intervenção do professor.

O que fica claro, portanto, é que o papel de reelaborador, na correção resolutiva, é do professor, e unicamente dele. É o professor que pensa pelo aluno e age como julga que o aluno deveria agir, na reelaboração do texto.

Pelo fato de o aluno receber não só a informação sobre o seu problema como também a resolução pronta para ele, compete-lhe apenas copiar as soluções encontradas pelo professor, que as deixou registradas ou no próprio corpo do texto ou na margem. Em termos de construção de conhecimento sobre aspectos fonológicos, morfológicos, sintáticos, semânticos ou pragmáticos, porém, o investimento é nulo. É de se perguntar, nesse sentido, se o mesmo efeito - ou maior - não seria atingido com a cópia de um texto de boa qualidade de um autor consagrado qualquer.

Em termos enunciativos, há uma relação $e u$ - $t u$ reconhecível: o professor, na posição de leitor, interage com o sujeito que diz, passando da posição de $t u$ para o qual se dirige o discurso para a posição de eu, que enuncia para aquele que, antes, se dizia eu. Tal relação, contudo, se aproxima muito mais do monólogo do que do diálogo constitutivo. O que o professor diz anula o outro - o aluno (RUIZ, 2010). Não há equilíbrio entre os dois sujeitos, e o enunciador-professor se sobrepõe ao enunciador-aluno.

${ }^{1}$ Muito embora se saiba da importância de que se revestem as formas de encaminhamento dos textos, por parte dos professores, bem como as atividades que precedem a produção do texto, tais aspectos não serão aqui abordados, dado o escopo deste trabalho. 
Além disso, como o professor só atua sobre a palavra ou o trecho que apresenta erro, não é o que se diz que ganha destaque, mas a forma como se diz. E como forma, aqui, se entende a ortografia, a acentuação, a pontuação, a concordância etc. Fica praticamente esquecido o sentido, não havendo, por isso, avaliação das estratégias do dizer, dos recursos estilísticos, da relação que se estabelece com o interlocutor etc.

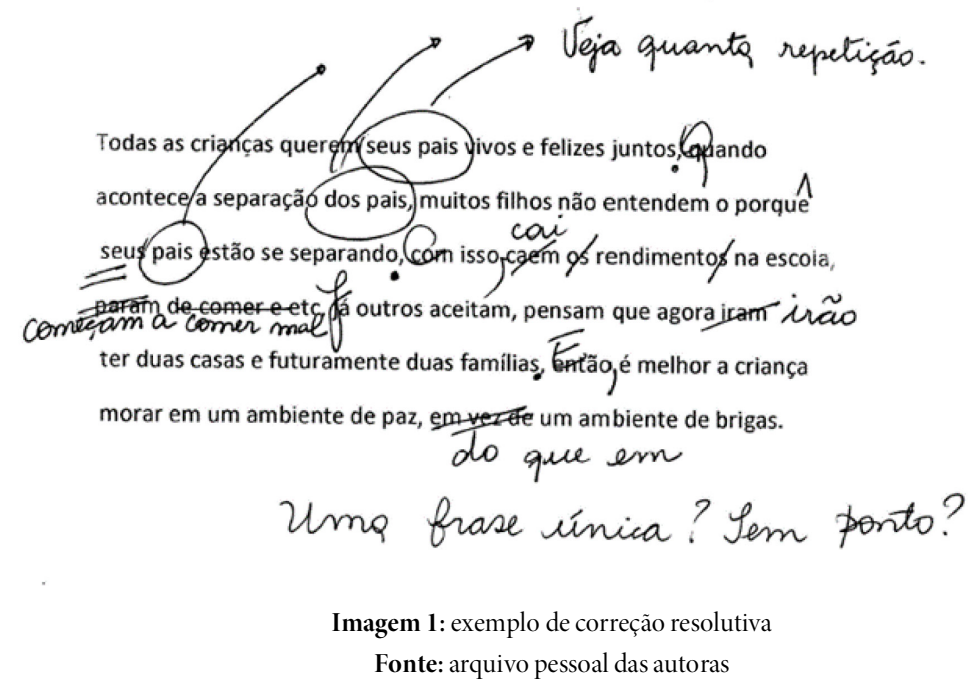

\subsection{CORREÇÃO INDICATIVA}

Na correção indicativa, o professor também atua sobre aspectos bastante pontuais do texto, por isso abrangendo problemas como os da ordem da ortografia, da pontuação e da adequação vocabular, por exemplo. O professor não procede a alterações no texto, apenas indica o problema, sendo que a resolução deste fica a cargo do aluno. O professor assinala os problemas encontrados de duas diferentes formas: a) indicando-os no próprio corpo do texto, através do destacamento da palavra por meio de um sublinhado, de um círculo ou de uma flecha, por exemplo, ou fazendo um X no ponto em que detecta o(s) problema(s); b) indicando-os na margem do texto, através de sinalizações - um asterisco, um X, ou uma chave.

No caso de apontamentos feitos no corpo do texto, a detecção do problema é facilitada para o aluno, uma vez que a palavra ou a expressão em que há alguma forma de desvio virá marcada de algum modo. Já a indicação de problema feita na margem exige uma reflexão um pouco maior de sua parte, haja vista que o limite para que o problema seja identificado é ampliado para uma linha. De qualquer forma, via de regra, a linha parece ser o limite para as observações.

Muito embora a relação entre diferentes segmentos possa ser apontada por essa estratégia, não é comum que isso ocorra. Questões relacionadas à coesão e à coerência, por exemplo, muitas vezes demandam que esse tipo de correção seja explorado concomitantemente a outra estratégia, para dar conta de aspectos mais amplos. Assim, quando um determinado segmento é incoerente em relação a um enunciado anterior, é preciso que, além de se apontar a incoerência nesse ponto, o autor seja remetido ao segmento anterior com o qual não há uma relação de continuidade. Em geral, nesses casos passam a ser usados os chamados bilhetes, na sequência detalhados, no tópico correção textual-interativa.

A correção indicativa representa, para o aluno, uma dificuldade consideravelmente maior se comparada com a resolutiva, anteriormente citada, na qual o professor trata de reescrever o texto, em vez de criar uma situação que leve o aluno a fazê-lo. Mesmo que numa instância reduzida - a da linha-, a estratégia de apenas indicar o erro leva o aluno a uma releitura do seu texto, o que, por sua vez, leva-o a um processo de interlocução com o professor, que leu o texto e apresenta, por meio de um código - mesmo que bastante sucinto -, sua leitura crítica daquele enunciado. Sendo assim, a reescritura, de tal modo conduzida, leva o aluno a repensar o seu texto. 
Especialmente, há que se considerar o fato de a correção indicativa reconhecer o sujeito enunciador e buscar despertar nele a reflexão sobre os fatos da língua. Há, dessa forma, uma relação $e u / t u$ perceptível entre os sujeitos aluno/professor, numa dimensão um pouco mais linear do que a percebida na correção resolutiva.

Muito embora tal relação se caracterize pela verticalidade - alguém que sabe versus alguém que não sabe, o que inevitavelmente acontece no processo de ensino e de aprendizagem -, o aluno é chamado a refletir sobre o seu próprio texto: cabe a ele perceber as incongruências e, a partir das sinalizações do professor, reconstruir o seu enunciado.

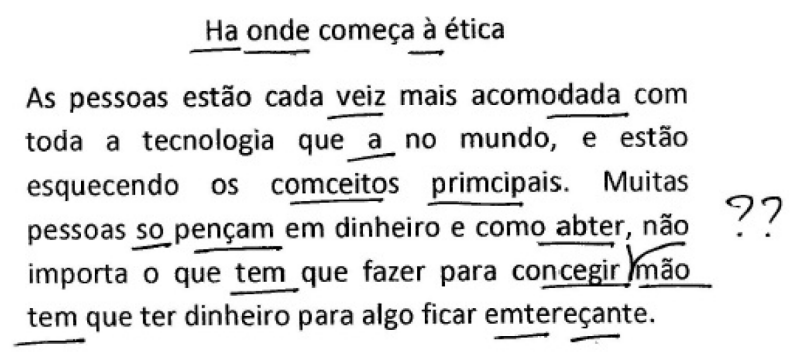

Imagem 2: exemplo de correção indicativa

Fonte: arquivo pessoal das autoras

\subsection{CORREÇÃO CLASSIFICATÓRIA}

Na correção classificatória, é criado um conjunto de símbolos, que, em geral, aparecem escritos na margem do texto, os quais classificam o problema encontrado e que está assinalado - sublinhado ou circulado - no texto. Assim, por intermédio de um conjunto de símbolos - frequentemente abreviações -, o professor propõe ao aluno que solucione os problemas detectados.

Os símbolos podem variar em sua quantidade de acordo com a série em que se encontram os alunos - e, consequentemente, o nível de conhecimento sobre o código escrito que detêm - e os objetivos específicos do professor naquele determinado texto. Numa sétima série em que o professor esteja trabalhando com as relações criadas a partir das conjunções, pode-se dar mais destaque a essa questão e somente serem utilizados símbolos que remetam à coordenação, por exemplo. Já nas séries iniciais do ensino fundamental, tal preocupação não caberia, podendo o professor usar símbolos que remetessem a questões bem mais simples, como o uso de letra maiúscula, a paragrafação, a indicação de discurso direto, dentre outros.

São alguns exemplos de símbolos: M (minúscula); CP (colocação pronominal); EF (estrutura da frase); EI (erro de informação). Como se vê, os problemas assinalados podem pertencer a diferentes ordens, incluindo desde aspectos bastante formais da escrita até outros, ligados à estrutura do texto como um todo ou à situação enunciativa em andamento.

A correção classificatória, de acordo com Ruiz (2010), pode explorar códigos enquadráveis em pelo menos cinco grupos distintos: convenções da escrita, norma culta, estruturação frástica, léxico e organização textual. Isso deixa entrever uma preocupação mais acentuada com os aspectos formais e relativos, ainda, à frase, porém sem negligenciar a unidade do texto.

Há, implícita nesse tipo de correção, a exemplo do que também fica evidente na resolutiva e na indicativa, a dicotomia entre uma linguística das formas e uma linguística enunciativa, uma postura formal e uma postura funcional da linguagem. A prática cotidiana das aulas de língua revela uma postura teórica herdada do estruturalismo -, em oposição a uma postura enunciativa, nos termos definidos por Benveniste (2005). Muito embora tenha de se admitir que as correções classificatória e indicativa dão indícios de uma postura que reconhece o texto como enunciação, a predominância ainda é de uma postura formalista. 
Em termos enunciativos, perdura uma relação vertical entre os sujeitos, em que um se impõe sobre o outro. Apesar disso, há uma dialogicidade maior aqui do que na correção resolutiva: o eu que produz o texto é chamado a dialogar quando questionado pelo $t u$ acerca de determinada estrutura.

Não se trata de uma imposição, mas de algo que se aproxima de uma negociação. Há, é claro, o reconhecimento da autoridade do alocutário (que se torna locutor quando enuncia, marcando aquilo que julga, no texto, inadequado). Mesmo assim, parece salvaguardada a condição do aluno como autor do seu texto, ou seja, de enunciador que se apodera da língua e que age sobre ela, rearranjando-a de maneira a melhor interagir verbalmente.

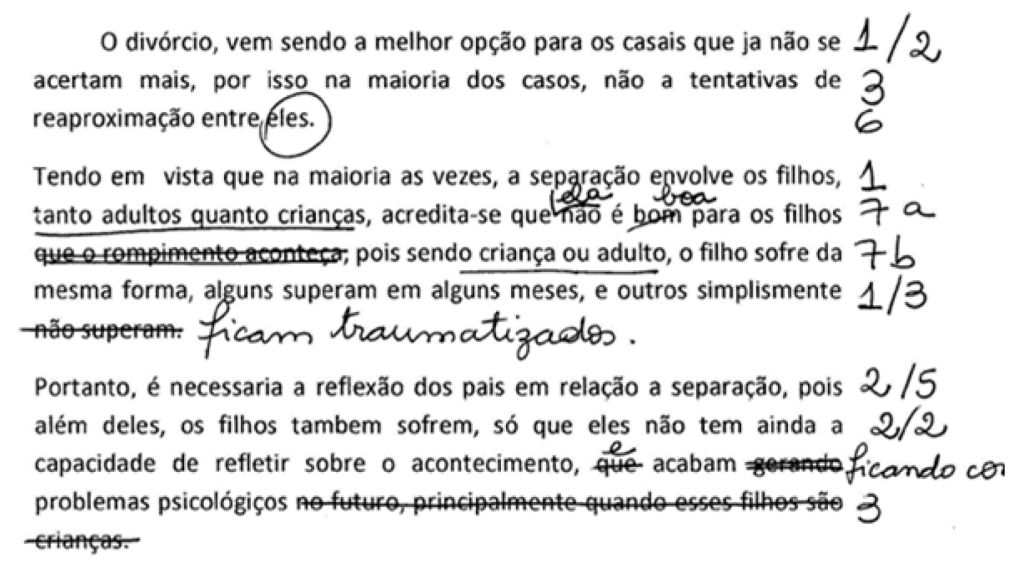

Imagem 3: exemplo de correção classificatória

Legenda utilizada no texto: 1) erro de pontuação; 2) erro de acentuação; 3) erro de ortografia; 4) problemas de concordância; 5) questão de regência e crase; 6) referente do termo; 7) repetição; 8) ligação entre as ideias.

Fonte: arquivo pessoal das autoras

\subsection{CORREÇÃO TEXTUAL-INTERATIVA}

A correção textual-interativa compreende comentários mais longos do que aqueles que ocupam a margem do texto, sendo estes geralmente feitos no espaço logo após o texto. São, segundo Ruiz (2010), pequenos bilhetes com duas funções básicas: falar acerca da revisão a ser feita pelo aluno ou falar, metadiscursivamente, sobre a própria tarefa de correção por parte do leitor-professor.

Tal estratégia consiste numa alternativa às demais formas de correção, especialmente considerando que certos tipos de ocorrência ou são amplos demais para serem circunscritos no texto ou não são passíveis de observação de outra maneira que não através dessa espécie de carta. De certa forma, a escrita do professor após o texto do aluno representaria uma alternância de turnos entre os sujeitos envolvidos, tornando visível a relação entre locutor e alocutário, podendo, inclusive, surgir comentários a respeito do empenho do aluno na construção do seu texto ou sobre a demonstração de maior domínio de estratégias linguísticas que passou a demonstrar em função da reescritura.

O bilhete, assim, pode ser um espaço para o elogio, para a cobrança do aluno quanto a algum aspecto mais global do seu texto ou mesmo para explicar algum código utilizado no corpo do texto ou na sua margem. Em todos os casos, porém, transparece uma relação de reconhecimento entre os sujeitos envolvidos.

Por fim, a diferença fundamental dessa estratégia em relação às demais é que nela o professor 
[...] toma como objeto de discurso de sua correção não mais o modo de dizer do aluno [...], mas também o dizer desse aluno, ou a atitude comportamental (não verbal) desse aluno refletida pelo seu dizer (ou seu não dizer), a propósito da correção do professor; ou, ainda, a própria tarefa interventiva que ele mesmo, professor, está realizando no momento. (RUIZ, 2010, p. 56-57).

Nessas avaliações, ocorre uma postura mais reflexiva por parte do professor, que chama à reflexão também o aluno. O professor registra por escrito a reflexão que fez acerca do que disse o aluno e da forma como o disse. Cabe, então, ao aluno, "ler a leitura" que o professor fez do texto, estruturando-o de tal maneira que venha a ser possível ao professor lê-lo, depois, como ele - o aluno realmente gostaria que fosse lido, e não como o foi.

Os bilhetes fazem referência a problemas ligados à relação forma/conteúdo, cuja resolução demanda um olhar menos superficial e uma revisão mais aprofundada, por envolver uma cadeia de informações ou de estruturas ao longo do texto. Em geral, tal estratégia aparece combinada com a da correção indicativa ou classificatória, que foca nos aspectos mais localizados, referentes à forma. Essa combinação de procedimentos é, segundo Ruiz (2010), a mais eficaz para desenvolver a competência comunicativa do aluno. Uma hipótese para isso é que, ao produzir o bilhete, o professor se coloca enquanto sujeito da enunciação, reconhecendo o seu interlocutor. Não o desmerece, mas dialoga com ele. Não o assujeita. Enfim, evidencia-se a intersubjetividade, na reversibilidade $e u / t u$.



Imagem 4: exemplo de correção textual-interativa

Fonte: arquivo pessoal das autoras

\section{ALGUMAS CONCLUSÕES}

Estudos recentes sobre a discussão e a reconstrução de textos escolares têm apontado a importância dos modos de participação do outro para a construção de uma maior habilidade enunciativa dos sujeitos, tanto na forma oral quanto na escrita. Daí a relevância de se pensar as formas de intervenção do professor no texto do aluno, de maneira a desencadear a reconstrução textual.

Distanciar-se do próprio texto é necessário para melhor estruturá-lo, uma vez que permite observá-lo e avaliá-lo criticamente, na perspectiva do outro - o leitor, mesmo que virtualmente concebido. Esse deslocamento enunciador-enunciatário compõe a essência de uma postura autônoma de produção de textos, sendo que, por isso, o professor não pode se restringir à identificação de problemas textuais, especialmente os de ordem ortográfica. A ele cabe a função de desencadear o processo de reflexão do aluno com vistas a levá-lo a "perceber a percepção" do outro, trazendo, então, para um nível de consciência, os recursos empregados no enunciado e os recursos disponíveis para o alcance dos seus propósitos enunciativos. 
Tal alternância, que evidencia o reconhecimento do outro no discurso, se dá em diferentes momentos. O movimento inicial ocorre quando o professor lança uma proposta de produção de textos, colocando-se como eu e instaurando o aluno como tu. É esse movimento que dá origem a todos os demais, subsequentes, uma vez que seus reflexos podem ter implicações posteriores. Posto que, tradicionalmente, a produção textual na escola tem um caráter de obrigatoriedade, de tarefa, e não emerge, necessariamente, de uma vontade discursiva do falante, a elaboração do enunciado da proposta deve ser criteriosa: ela precisa de fato instigar o outro à participação, de maneira que ele, na posição de alocutário daquela enunciação do professor, tome para si a posição de eu, ou seja, de locutor.

Instituído como sujeito, o aluno passa a ocupar, então, a posição de $e u$ da enunciação, alternando sua posição com a do professor, que passa a constituir-se como $t u$, ou seja, como leitor institucionalmente estabelecido do texto. Eis o segundo movimento, originado, como se disse, da proposta de produção lançada. Cabe ao aluno produzir um texto que seja condizente com a proposta feita pelo professor. Diversas habilidades precisam ser mobilizadas para tanto, desde questões ligadas basicamente à estrutura do texto como também outras, referentes ao processo de interlocução em si.

No caso de o aluno ter como parâmetro de interlocução do seu texto escrito um sujeito interessado apenas na correção de linguagem, ele tenderá a produzir apenas formas vazias de conteúdo, tendo em vista que o conteúdo ficará num segundo plano. A produção do texto, assim, é tomada por ele como um ato mecânico totalmente desvinculado de significação. Daí a importância de que as propostas de produção lançadas em sala de aula tenham sempre um propósito efetivo de interlocução, sendo que a forma deverá servir, nessa medida, unicamente aos fins sociointerativos, na perspectiva teórica apontada por Bakhtin (2003) e Benveniste (2005).

Se observado esse aspecto, o aluno, na posição de eu que tem algo a dizer, constitui-se enquanto autor, com vistas à interação efetiva com o outro, que pode ser o professor, mas não precisa ser necessariamente ele, ou apenas ele: podem estar também nessa posição os colegas, os pais, a comunidade. O texto tornado público ganha relevância na medida em que cumpre a sua função de estabelecer a interlocução entre sujeitos, que implica troca, negociação de sentidos.Para que isso ocorra, algumas etapas prévias são necessárias: em primeiro lugar, não se pode escrever do nada - é preciso que se pesquise sobre o assunto, que sejam lidos textos de referência, sejam eles sobre o assunto ou sobre o gênero em pauta, o que possibilitará a escrita individual.

Produzido o texto, invertem-se os papéis enunciativos: o aluno, que era inicialmente, alocutário em relação ao professor, passa a ser o locutor, enquanto o professor, que convocara para a participação, passa de locutor para alocutário. A proposta anteriormente lançada pelo professor é efetivada pelo aluno, que atualiza a língua para servir aos seus propósitos. O aluno mobilizará aquilo que julga ser importante para o seu alocutário - o professor. No caso de uma excessiva ênfase em aspectos ligados à ortografia, por exemplo, o aluno tende a responder à proposta privilegiando essa dimensão.

A ideia de produzir um texto sempre está vinculada à percepção do outro, enquanto alocutário. Afinal, que sentido faria dizer algo para o vazio? É necessário, portanto, que o professor se coloque na posição desse alocutário, o que implica uma postura de disponibilidade para interagir com o outro por meio da escrita, construindo colaborativamente os sentidos propostos pelo enunciador-aluno.Quando se fala em "construir sentidos", isso implica, no caso do professor, colocar-se como leitor e sujeito capaz de auxiliar o aluno a qualificar o seu texto, e não como caçador de erros ou como aquele que atribui uma nota ao texto, dando-o como produto final.

Nessa leitura do professor, ocorre uma nova troca de papéis enunciativos: da posição de alocutário, ele assume novamente a posição de locutor, na medida em que lhe cabe analisar, avaliar o texto produzido pelo aluno e dar-lhe retorno sobre a produção. Entretanto, se o professor se coloca apenas como uma autoridade avaliativa do enunciado, as escolhas enunciativas do aluno tendem a ser para um sujeito (coenunciador) assim configurado, e não para um tu a quem se tem algo a dizer. Que postura, então, deve adotar o professor com vistas a efetivamente se colocar como locutor atento e, mais do que isso, auxiliar o aluno desenvolver as suas habilidades linguísticas?

Fórum linguistic., Florianópolis, v.13,n.3,p.1415-1429, jul./ set.2016. 
O procedimento adotado pelo professor interfere no processo de qualificação do texto do aluno. Parece consenso que quanto mais evidente ficar a relação de interlocução entre aluno e professor, maiores serão os resultados da aprendizagem de estratégias e procedimentos discursivos. Até mesmo por isso a reescritura não pode estar focada unicamente no domínio de regras, muito embora elas tenham, obviamente, sua importância na construção de sentidos. A atitude prescritiva, porém, não combina com uma postura dialógica, o que também não significa dizer que qualquer coisa que seja dita deva ser considerada pelo professor. Denotase, então, a necessidade de uma postura interlocutiva do professor, não só lendo, grifando erros gramaticais e atribuindo nota, mas sim ajudando o aluno a reelaborar o enunciado de modo a melhor construí-lo, a organizá-lo para obtenção dos propósitos comunicativos e dos sentidos que busca estabelecer por meio do texto.

O trabalho com o texto numa perspectiva intersubjetiva implica o reconhecimento, por parte do aluno, do outro representado pelo professor. Esse leitor pré-estabelecido existe mesmo nas situações em que são produzidos textos de gêneros variados, explorando suas propriedades discursivas, temáticas e composicionais, como críticas de filmes para uma semana de cinema a ser realizada na escola, anúncios classificados sobre serviços prestados na comunidade ou uma carta do leitor a ser enviada a um jornal da cidade. Mesmo nessas situações, em que há um outro leitor em vista - um possível participante da semana de cinema, um cliente em potencial ou os leitores de um jornal -, o professor se configura como leitor primeiro, a quem caberá auxiliar o aluno a melhor lidar com diferentes maneiras de relacionar a forma e o conteúdo, cuidando tanto de aspectos formais do código escrito como funcionais, relacionados ao propósito de determinado gênero, às informações nele veiculadas, à resposta esperada do leitor.

Compete ao professor colocar-se como mediador do desenvolvimento da escrita, tanto em seus aspectos formais quanto funcionais. Parece claro, porém, que práticas que tomam o texto como unidades de sentido e, portanto, como instância comunicativa entre um $e \mathfrak{u}$ e um $t u$, têm mais chances de alcançar o sucesso do que aquelas que veem o texto como depósito de ocorrências gramaticais enquadradas ou não dentro da norma culta.

Quando o professor dá ao aluno retorno sobre o seu texto, a estratégia que ele adota deixa entrever os aspectos que ele julga relevantes para a construção do enunciado e, também, a relação que ele estabelece com tal sujeito: uma relação de mediação para o alcance do conhecimento, constituindo-se, portanto, como sujeito interlocutor do aluno; ou uma posição prescritiva, que desconsidera qualquer intersubjetividade inerente ao processo de comunicação.

Nesse último caso, a escola cria uma espécie de distanciamento entre o eu e o $t u$, um protocolo de afastamento, um hiato, o que se manifesta tanto na produção do texto quanto na intervenção que o professor faz nele: em nenhuma dessas instâncias há reconhecimento do outro.

\section{REFERÊNCIAS}

ANTUNES, Irandé. Língua, texto e ensino outra escola possível. São Paulo: Parábola Editorial, 2009.

BAKHTIN, Mikhail. Os gêneros do discurso. In: Estética da criação verbal. 4.ed. São Paulo: Martins Fontes, 2003. p. 261306.

BAKHTIN, Mikhail. O problema do texto na lingüística, na filologia e em outras ciências humanas. In: $\mathrm{n}: \ldots$ Estética da criação verbal. 4.ed. São Paulo: Martins Fontes, 2003. p. 307-335. 
BENVENISTE, Émile. Observações sobre a função da linguagem na descoberta freudiana. In: . Problemas de lingüística geral I. 5. ed. Campinas: Pontes Editores, 2005. p.81-94.

A natureza dos pronomes. In: . Problemas de lingüística geral I. 5. ed. Campinas: Pontes Editores, 2005. p. 277-283.

. Da subjetividade na linguagem. In: Problemas de lingüística geral I. 5. ed. Campinas: Pontes Editores, 2005, p. 284293.

FIORIN, José Luiz. Pragmática. In: (Org.). Introdução à lingüística: princípios de análise. 4. ed. São Paulo: Contexto, 2010. v. 2. p. 161-185.

LEAL, Leiva de Figueiredo Viana. A formação do produtor de texto escrito na escola: uma análise das relações entre os processos interlocutivo e os processos de ensino. In: VAL, Maria da Graça Costa; ROCHA, Gladys (Org.). Reflexões sobre práticas escolares de produção de texto: o sujeito-autor. Belo Horizonte: Autêntica/CEALE/FaE/UFMG, 2008. p. 53-67.

RUIZ, Eliana Donaio. Como corrigir redações na escola: uma proposta textual-interativa. São Paulo: Contexto, 2010. 